\title{
Analysis on the Outflow Conditions about the Foreign Trade Commodity Supply in Fujian Province
}

\author{
Lin $\mathrm{Yu}$ and Chen Zhong \\ Fuzhou University of International Studies and Trade
}

\begin{abstract}
In the recent years, the outflow phenomenon of export commodity supply in Fujian Province is relatively prominent, and presents the trend of expansion year by year. The paper analyzes the overall outflow conditions about the export commodity supply in the province from several aspects, including the outflow scale of export commodity supply, the main outflow commodities, the main flow direction of outflow commodities, and points out several factors causing the continuous outflow of commodity supply, pointedly puts forward political suggestions about perfecting the port hardware and software facilities, cultivating the new business type of foreign trade, innovating customs supervision mode and promoting the commodity supply backflow.
\end{abstract}

Keywords-Outflow of export commodity supply; The new business type of foreign trade; Business environment

\section{INTRODUCTION}

Under the opened regional economic mode, the flow direction of commodities tends to be diversified, and the phenomenon of commodity supply outflow is increasingly serious, and has even caused various places competing for resource supplies, and as for commodities that are well sold abroad, with good operation profits, there can always be conditions such as raising the commodity price for panic purchasing, and the commodity supply outflow. In the recent years, the phenomenon about the outflow of export commodity supply in Fujian Province is relatively prominent, and presents a trend of expansion year by year.

\section{ANALYSIS ON THE OUTFLOW CONDITIONS ABOUT THE} EXPORT COMMODITY SUPPLY OF FUJIAN PROVINCE IN THE RECENT YEARS

\section{A. (I) Outflow Scale of Export Commodity Supply}

In 2015, the outflow for the export commodity supply in Fujian was RMB 27.271 billion, and in 2016, it reached to RMB 34.755 billion, and then RMB 45.107 billion in 2017, presenting an increasingly serious trend.

TABLE I. OUTFLOW CONDITIONS ABOUT THE EXPORT COMMODITY SUPPLY IN FUJIAN PROVINCE FROM 2015 TO 2017

\begin{tabular}{c|c|c|c}
\hline Year & 2015 & 2016 & 2017 \\
\hline $\begin{array}{c}\text { Total outflow amount of export } \\
\text { commodity supply }\end{array}$ & 272.71 & 347.55 & 451.07 \\
\hline
\end{tabular}

\section{B. Main Commodities for the Outflow of Commodity Supply}

In 2016, the outflow commodities in Fujian Province mainly included RMB 10.196 billion refined oil products (RMB 5.26 billion gasoline, RMB 4.343 billion diesel, RMB 479 million other fuel oil and RMB 115 million coal oil), RMB 9.854 billion traditional labor-intensive products (RMB 5.906 billion textiles and garments, RMB 2.127 billion shoes, and RMB 739 million bags and similar containers), RMB 7.43 billion mechanical and electrical products (of which, there were RMB 2.837 billion electrical appliance and electronic products, RMB 2.135 billion mechanical equipment, and RMB 716 million metal products), RMB 4.166 billion textiles and yarns, fabrics and products (RMB 148 million cotton woven fabrics, and RMB 19 million synthetic staple fibers and Cotton blended machine fabrics), RMB 2.132 billion high-tech products (RMB 1.185 billion computer and communication technology products, RMB 230 million electronic technology products, and RMB 386 million computer integrated manufacturing technology products), RMB 1.91 billion rolled steels (RMB 1.45 billion iron and steel sheets and plates, RMB 165 million steel bars), RMB 1.69 billion agricultural products and RMB 548 million vegetables.

In 2017, the outflow commodities in Fujian Province mainly included RMB 16.807 billion refined oil products (RMB 8.478 billion gasoline, RMB 7.333 billion diesel, RMB 660 million other fuel oil and RMB 335 million coal oil), RMB 8.66 billion mechanical and electrical products (of which, there were RMB 3.363 billion electrical appliance and electronic products, RMB 2.346 billion mechanical equipment, and RMB 980 million metal products), RMB 4.166 billion textiles and yarns, fabrics and products (RMB 74 million cotton woven fabrics, and RMB 17 million synthetic staple fibers and Cotton blended machine fabrics), RMB 11.268 billion traditional labor-intensive products (RMB 6.791 billion textiles and garments, RMB 2.524 billion shoes, and RMB 747 million bags and similar containers), RMB 2.116 billion rolled steels (RMB 1.765 billion iron and steel sheets and plates, RMB 69 million angle irons and fashioned irons), RMB 1.924 billion high-tech products (RMB 1.226 billion computer and communication technology products, RMB 190 million electronic technology products, and RMB 118 million computer integrated manufacturing technology products), RMB 2.108 billion agricultural products and RMB 685 million vegetables. 
According to statistics, in the first half year of 2018, the "commodity supply place within the territory" declared by Fuzhou Customs and Xiamen Customs was Fujian, but the scale for the export that took enterprises outside of the province as the operation units was about RMB 20 billion, of which Xiamen Customs was about RMB 15.8 billion, and Fuzhou Customs was about RMB 4 billion. According to the data analysis provided by the customs, commodities that were exported with nonlocal enterprises being regarded as the operation unit mainly include RMB 8.33 billion Quanzhou Sinochem refined oil products, and about RMB 800 million cold and hot rolled plates produced by Ningde Region of our province and exported under the agency of Shanghai Dingxing, Qingshan Holding and other enterprises; about RMB 1.4 billion textiles and garments and about RMB 900 million shoes exported at Xiamen Customs District; about RMB 700 million mechanical and electrical products at Fuzhou Customs District, and about RMB 1.1 billion textiles, garments, shoes, ceramics and stones, furniture and other traditional commodities.

\section{Main Flow Direction of Outflow Commodities}

As can be seen from the outflow place of commodity supply, the foreign trade commodity supply in Fujian Province mainly flows to Guangdong, Shanghai, Zhejiang, Jiangsu and other developed provinces along the coast. The main port supplied thereby includes Guangzhou, Shenzhen, Nanjing, Shanghai, Hangzhou and other foreign province port companies. The logistics industry in these provincial ports is highly developed, and is set with port inspection area, port auxiliary area, storage logistics area, international transfer area, purchasing distribution area, processing and manufacturing area, commerce and trade service area and other functional areas, and pointedly develops international transfer, distribution, purchasing, transit trade, export processing and other businesses, expands financial trade, credit insurance and other relevant functions, and can facilitate the export of foreign trade commodities, and obviously decrease the operation cost of foreign trade enterprises. The two port groups of Pearl River Delta and Yangtze River Delta energetically develop multimodal transport, deeply expand port hinterland, attract the transfer of nonlocal commodity supplies, and can generate relatively serious distribution of commodity supplies in our province, and then influence the development of port group in our province.

\section{ANALYSIS ON THE OUTFLOW REASONS OF EXPORT COMMODITY SUPPLY IN FUJIAN PROVINCE}

The outflow of export commodity supply in Fujian Province is influenced by factors of all aspects, and due to reasons such as small enterprise scale, weak foreign trade operation capacity, insufficient government fund and political support strength, unsound foreign trade talent cultivation and exhibition platform construction as well as the lack in leading foreign trade service enterprises, this has caused the severe outflow situation of commodity supply.

\section{A. The Comprehensive Competitiveness of the Port isn't Strong Enough}

The outflow of foreign trade commodity supply is closely related to the insufficient port competitiveness in Fujian Province, and this is specifically reflected in the insufficient development of port hardware and software as well as logistics industry, while the essential reason causing the insufficient development of port hardware and software as well as logistics industry is the small economic aggregate of the province, and the narrow economic hinterland. Due to the restriction of geological conditions and traffic conditions, the port hinterland has been restricted inside the territory of the province for a long time, and the hinterlands of Hunan, Jiangxi and other places are also facing the situation of being attracted by the two big port groups of Pearl River Delta and Yangtze River Delta. The hinterland commodity supply of the port flows towards the Yangtze River Delta Port Group in north, and is absorbed by the Pearl River Delta Port Group in south.

\section{B. The Customs Clearance Environment Still Needs to be Optimized}

The port informatization degree, customs clearance time, inspection rate, customs clearance procedures, etc. are to be further perfected, and the customs clearance environment and customs clearance efficiency are to be improved, and can promote cross-border trade convenience. For instance, the customs move the online verification of port clearance electronic data from the electronic examination link to the customs clearance form release link through optimizing the customs clearance operation procedures for enterprise commodity customs clearance, and the customs clearance mode has realized the conversion from the previous "serial type" operation to "parallel-type" operation, and brought lots of convenience for export and import enterprises to carry out cross-border trade.

\section{Political Difference has Caused the Aggravation of Commodity Supply Competition in Different Places}

Various brother provinces have successively enlarged the attraction of export commodity supply. From January to May, 2017, Jiangxi Province has enlarged the absorption strength of commodity supply outside of the province, and the net inflow was RMB 39.76 billion, which was increased by RMB 29.85 billion on a year-on-year basis. Since 2016, Yidatong Company established 31 branches at various places nationwide, and lots of commodity supplies originally exported through Fujian Yidatong in Jiangxi, Hunan, Hubei and other places are requested to be exported in the name of the local company, and this has caused the part of commodity supply outside of the province in Fujian Yidatong was distributed by about RMB 3.03 billion during the first half year of 2017. As for the surrounding provinces and cities, they adopt "market purchasing" or "tourism shopping" and other new business types, and use relatively high subsidies, and convenient customs clearance to reinforce and attract the commodity supply of our province. According to statistics, from January to May, 2017, the export in Zhejiang Province was RMB 76.24 billion as per the mode of market purchasing trade, the export in Guangzhou for market purchasing was RMB 10.47 billion, 
and the export of tourism shopping was RMB 94.34 billion (which was increased by 1.2 times), and partial commodity supplies in Fujian Province flows to the aforementioned market for export.

\section{Lack in Large-scaled Foreign Trade Comprehensive Service Enterprises}

The comprehensive foreign trade service company exerts the function of agency and platform, and the enterprise signs tripartite contract with clients and comprehensive foreign trade service company, and the foreign trade service company charges service expenses therein; comparatively speaking, enterprises can be encountered with big input and the easy loss of personnel when independently cultivating professional foreign trade personnel, so it is more attractive for SMEs to select comprehensive foreign trade service company. Some large-scaled comprehensive foreign trade service companies outside of the province have advantages such as fast funds to the account as well as simple and convenient procedures, and this can facilitate SMEs to fast withdraw funds. Some professional export and import companies in Fujian Province have weak external sales capacity, narrow external sales channel, and bad operation status, and some enterprises are also subject to loss problems, with heavy burdens and enlarged corresponding expenditures, so the acquisition price given at home has no competitiveness, and will result in some commodities flowing into companies of other provinces.

\section{E. Insufficient Foreign Trade Capacity of the Enterprise}

Nanping City reflects that, the tea of the city is basically acquired by companies of other provinces as per the form of raw materials and then processed and exported, for instance, the commodity value for the annually 20,000 dan output of Zhenghe White Tea is about RMB 60 million, and the export in local is merely RMB 6 million; Ningde City reflects that, the annual average export loss for the local tea is about RMB 700 million. The enterprises of textile and garment, shoes and hats in Nanping are mainly small and micro-enterprises, without the first-hand foreign trade order; they can only undertake and process the orders of trade companies outside of the province, and the annual average export loss is about RMB 150 million. Even if there are partial enterprises carrying out foreign trade business, due to the insufficient capacity in expanding market and signing orders, generally, they can merely sell products to foreign trade companies outside of the province as their export agencies, for instance, Quanzhou Jiacheng Leather Gloves newly increased above USD 10 million orders this year, but they are mainly supplied to the nonlocal companies for export.

\section{F. Headquarter-type Project Deployment Restriction}

Partial headquarter-type projects in Fujian Province are restricted by headquarters, and the export data are only deployed by headquarters. For instance, RMB 8.33 billion export data of Quanzhou Sinochem during the first half year are reflected in Beijing Headquarter, and the export volume of Fujian Haixi Automobile from the headquarter of Haixi Truck exceeds RMB 200 million in the first half of the year, and there are also similar conditions in Ningde Dingxin Group, and Zhangzhou Mengshi Company.
Besides, enterprises are not familiar with the foreign trade statistics, and this has caused the loss of data. Due to problems such as assigned foreign clients and freight forwarding in partial enterprises of Fujian Province, commodity customs clearance will generally enter into bonded warehouse and other special supervision area (some of them are even the special supervision area outside of the province), and then enterprises outside of the province will declare for departure. According to the data measurement provided by Xiamen Customs, there are about RMB 300 million departure data declared by companies of different places in Xiamen Customs District Bounded Warehouse only, and this excludes the data entering into the special supervision area outside of the province.

\section{Political Suggestions ABOUt PROMOting COMMODITY SUPPLY BACKFLOW}

Under the current big market, big foreign trade and big circulation operation environment, it is impossible and unrealistic to control the outflow of commodity supply, and it also goes against the economic development rules of the market. Thus, it is requested to pointedly release relevant support and preference policies, and further optimize the business environment, which can be good for guiding the export commodity supply backflow, and promote export development.

\section{A. Perfect the Port Hardware and Software Facilities, and Improve the Comprehensive Competition of the Port}

Promote the port integration of the entire province, constantly perfect port area collection and separation conditions, and comprehensively exploit offshore external access. Perfect the port facilities and equipment in Fujian Province, decrease port charging, optimize port service, and improve the comprehensive competition of the port in our province.

\section{B. Energetically Cultivate the New Business Type of Foreign \\ Trade, and Promote the Kinetic Energy Conversion of \\ Foreign Trade Development}

Firstly, it is to accelerate the cultivation of new advantages for foreign trade competition. Fujian Province is the core area for Marine Silk Road, and it has actively participated in "the Belt and Road" and international productivity, and can drive the constantly increased export of device manufacturing industry in our province as well as the constantly increased technical contents of export products and additional value. Private enterprises should accelerate the transformation upgrading steps, and strive to form the new foreign trade competition advantages taking technology, brand, quality, and service as the core.

Secondly, it is to promote and accelerate the development of the new business type for the comprehensive foreign trade service. Reinforce the cultivation and support strength for the comprehensive foreign trade service enterprises, better serve small and micro enterprises in Fujian Province and improve the market extension capacity, and conduct well the export financing service of small and micro enterprises. Decrease the 
export operation cost, match with the development of foreign trade service industry, and gain profits from service.

Thirdly, it is to accelerate the development of cross-border e-business, oversea location and other types of trade type. Closely communicate and coordinate with the supervision department, actively ask the Ministry of Commerce and other ministries to include Lijia Business City and Shishi Garment City into the national "market purchasing" pilots, promote customs and other departments to support Putian Hanjiang Business City, Jinjiang Land Port and other conditional markets and enterprise pilots to carry out "tourism shopping" trade and adjust the pilot enterprises.

\section{Innovate Customs Supervision Mode, and Further Improve the Trade Facilitation Level}

The customs shall implement WTO Trade Facilitation Agreement, and continuously promote the "simplicity" of customs clearance procedures, and under the precondition of compressing $1 / 3$ of current customs clearance time, it is requested to continuously promote customs clearance preparation, recompress the commodity picking time, and further compress the compliance cost for the import and export links of the container.

\section{Perfect the Export Credit Insurance and Financial Service, and Practically Decrease Enterprise Cost}

Utilize the export credit, export credit insurance and other policies, promote the export of large-scaled complete equipment, mechanical and electrical products and high-tech products, and meet the industrial transformation upgrading demands of countries and regions along the line.

\section{E. Optimize Business Environment, and Stimulate the Main Market Vitality}

It is requested to build international, legal and convenient business environment, practically decrease institutional transaction cost, and fully stimulate the main market vitality; deepen the reform of "streamlining administration and delegating power to the lower levels, combing power delegation and management, and optimizing service", accelerate the transformation of government functions, decrease micro-management and direct interference, and pay attention to strengthening macro-control, market supervision and public service.

\section{F. Adopt Multiple Measures, and Actively Attract Commodity Source Regression}

Firstly, it is to seek for new trade opportunities. The trend about the transfer of current labor-intensive industry towards Southeast Asia is irreversible, and has become increasingly intensified, but Southeast Asian countries are still in the initial development period of the industry, and the industrial chain configuration is not complete, it is applicable to guide the relevant cities to lead conditional enterprise sin our province to boldly walk out, build purchasing center, expand the export of industrial chain upstream products in these Southeast Asian countries, and expand new trade opportunities. For instance, Quanzhou Fengyi drove above USD 3,000 raw and auxiliary textile materials of Quanzhou exported to Cambodia in Cambodia Additional Construction Phase II Garment Factory Project.

Secondly, it is to further conduct in-depth analysis work about the outflow of commodity supply. Pointedly track 726 enterprises with big export commodity supply in Fujian Province, continuously reinforce the contact with Fujian and Xiamen Customs, consult and ask for providing in-depth and detailed conditions about the loss of export commodity supply, further conduct well analysis, decompose cities, guide the competent business departments of various places to carry out in-depth field investigation at enterprises, find out and verify conditions, conduct well the tracking and coping work, and timely solve the difficulties in the commodity supply backflow of enterprises. Through "one-enterprise and one-strategy" and "one-to-one" service, energetically promote the preservation of export data of Cartel Group, Haixi Truck and other enterprises in our province. By virtue of the strength of business association, know about the outflow conditions of industrial commodity supply, reinforce the tracking guidance for member enterprises, and help them to carry out the backflow work of commodity supply.

Thirdly, it is to strengthen presentation and promote policy implementation. Cooperate with the competent business departments of all cities, exert the function of business association, cooperate with customs, external management, credit insurance and other departments, continuously reinforce the presentation and training of various foreign trade policies, emphasize on the "export performance oriented" foreign trade policies, and make enterprises pay more attentions and know more about the importance of export volume and growth conditions.

Fourthly, it is to reinforce the incubation and cultivation work. Start the foreign trade enterprise incubation work, reinforce strength to cultivate foreign trade subject, and promote "domestic and overseas business, the conversion from zero to one, the promotion of small enterprises into enterprises above state designated scale, and the expansion of enterprises above state designated scale" of external trade enterprises, especially through carrying out foreign trade business incubation and cultivation for small and micro-enterprises "with products but no market", improve the enterprise order receiving capacity, realize autonomous export, and guard the commodity supply.

Fifthly, it is to coordinate and solve the difficult problems encountered by enterprises when expanding the commodity supply business in different places. As for key enterprises with serious decrease in commodity supply in different places during the first half year, track and implement enterprises one by one, understand about the difficult problems, actively coordinate and solve problems, reinforce the contact with the national tax, external management, customs and other departments, actively strive to gain support, reinforce information exchange, and build a loose and convenient trade environment for enterprises. Pointedly gain the support of the State Administration of Taxation, promote it to implement the relevant measures about serving the stable growth of foreign 
trade, and reinforce the coaching of key enterprises, and timely remind them of tax-involved business risk.

\section{CONCLUSION}

In recent years, with the increasing outflow of goods from fujian province, some goods are being bid up. It can be concluded from the analysis that the scale of the outflow of goods from fujian province is gradually increasing, and there are many kinds of goods from fujian province. Influenced by many ports, the outflow of goods has brought certain adverse effects to the development of fujian port group. Moreover, fujian port enterprises are small in scale and weak in competitiveness, and the government's policies do not have enough support. Therefore, if fujian port group wants to occupy a favorable position in the cargo diversion of many port groups, it is necessary to improve its comprehensive competitiveness, seek government support, and innovate management mode, so as to stand out from the future foreign trade challenges.

\section{REFERENCES}

[1] Chen Junyi. Actively Cultivate New Competition Advantages and Energetically Promote the Construction of Trade Strengthening Province in Fujian [J]. Development Research, 2018, (02).

[2] Research Group for the Branch of China Export \& Credit Insurance Corporation in Fujian. Export \& Credit Insurance Service Fujian Enterprise Export "Belt and Road" Market Research [J] Fujian Finance, 2018, (03).

[3] Huang Caiyun. Current Status about the Structure of Export Products in Fujian and the Optimization Strategies [J] Journal of Guangxi Normal University for Nationalities, 2017, (06).

[4] Zeng Liang. Comparative Research about the Cross-border E-business in Fujian and Zhejiang [J] Journal of Huanghe S\&T University, 2017, (01).

[5] Huang Caiyun. Empirical Research about the Export Trade Mode in Fujian Province [J] Journal of Huaihai Institute of Technology (Natural Science Version), 2017, (04). 